\title{
Desenvolvimento do Pensamento Algébrico: proposição de um modelo para os problemas de partilha
}

\author{
Development of Algebraic Thinking: proposal of a pattern for sharing problems
}

\author{
Jadilson Ramos de Almeida ${ }^{1}$ \\ Marcelo Câmara dos Santos ${ }^{2}$
}

\begin{abstract}
Resumo
Esse artigo tem por objetivo apresentar um modelo que possibilita a identificação de níveis de desenvolvimento do pensamento algébrico revelado por estudantes ao resolverem problemas de partilha. Nossa pesquisa foi realizada em duas etapas. Na primeira, construímos uma versão a priori do modelo a partir da produção escrita de 342 alunos do $6^{\circ}$ ano do ensino fundamental ao responderem 6 problemas de partilha. Na segunda etapa reaplicamos os problemas a 343 alunos dos anos finais do ensino fundamental da cidade do Recife, em seguida escolhemos 8 alunos para realizarmos uma entrevista de explicitação. As análises aqui apresentadas serão a partir da produção escrita e da entrevista realizada com esses 8 alunos. Ao final chegamos à proposição de um modelo de níveis de pensamento algébrico que vai desde o nível 0 , caracterizado pela ausência de pensamento algébrico, passando por um nível incipiente de pensamento algébrico (nível 1), por um nível intermediário (nível 2) e por um nível consolidado de pensamento algébrico (nível 3). Propomos, também, para cada nível, a partir do nível 1, três subníveis, que denominamos de subníveis A, B e C.
\end{abstract}

Palavras-chave: Modelo; Pensamento algébrico; Níveis de desenvolvimento; Problemas de partilha.

\begin{abstract}
This paper aims to introduce a pattern to enable the identification of different levels of development of algebraic thinking in students while solving sharing problems. Our research was conducted in two stages: during the first one, we built up an initial version of the pattern based on 342 sixth-graders (around 11 years old) through an analysis of their written answers to six sharing problems; in the second stage, we presented the same problems to 343 sixth to ninth-graders (11 to 14 years old) in the city of Recife. Next, we selected 8 students, who we interviewed for deeper explanations on their thinking. The analysis presented in this paper stems from the 8 students' interviews answers and written production. Finally, we developed a proposal for a pattern of different levels of algebraic thinking. The first one indicates the absence of algebraic thinking (Level 0). The second level is an incipient level of algebraic thinking (Level 1). The third level means an intermediate level of algebraic thinking (Level 2), while the last one shows that algebraic thinking has been consolidated (Level 3). In addition, we propose three sublevels for each level, starting from Level 1, which we have named sublevels A, B and C.
\end{abstract}

Keywords: Pattern; Algebraic Thinking; Development Levels; Sharing Problems.

Submetido em: 16/10/2017 - Aceito em: 08/12/2018 - Publicado em: 11/12/2018

${ }^{1}$ Doutor em Ensino de Ciências e Matemática pela Universidade Federal Rural de Pernambuco. Professor da UFRPE. Brasil. Email: jadilsonalmeida@ hotamil.com

2 Doutor em Sciences de L'education pela Université de Paris X. Professor da Universidade Federal de Pernambuco. Brasil. Email: marcelocamaraufpe@yahoo.com.br. 


\section{Introdução}

Autores como Lins e Gimenez (2005) consideram que o fracasso em álgebra significa, muitas vezes, o fracasso absoluto na escola, e que um dos principais obstáculos ao aprendizado da álgebra é que ela representa um momento de seleção na educação escolar. Ainda segundo esses autores, uma grande dificuldade no trabalho com a álgebra escolar é perceber a existência de uma ruptura epistemológica nessa passagem do raciocínio aritmético para o algébrico, o que demanda uma transição para a introdução de uma nova linguagem e forma de raciocínio lógico-matemático.

Talvez por conta disso, muitas pesquisas são realizadas com o propósito de entender o desenvolvimento do pensamento algébrico em crianças. Essas pesquisas vêm mostrando a necessidade de diversificar as atividades propostas aos estudantes com o intuito de desenvolver esse raciocínio matemático (Borralho \& Barbosa, 2011; Ponte \& Velez, 2011; Silva \& Savioli, 2012).

Entretanto, para fazer o aluno desenvolver o pensamento algébrico, além de o professor ter o domínio de situações que levem a isso, acreditamos que também seja necessário saber em que nível de desenvolvimento o aluno se encontra, pois, se o professor propuser situações que necessitem de um nível de desenvolvimento muito avançado para alunos que estejam em um nível básico, essas situações, provavelmente, não ajudarão no desenvolvimento do pensamento algébrico desses alunos, já que eles não conseguirão respondê-las.

Algumas pesquisas, como as de Fiorentini, Fernandes e Cristovão (2005) e as de Godino, Aké, Gonzato e Wilhelmi (2014), apontam a existência de níveis de desenvolvimento do pensamento algébrico de alunos. A pesquisa de Fiorentini, Fernandes e Cristovão teve por objetivo investigar as potencialidades pedagógicas das investigações matemáticas no ensino da álgebra elementar e, a partir de observações, indicam a existência de fases de desenvolvimento do pensar algebricamente. Já Godino e seus colaboradores tinham, em sua pesquisa, o objetivo de apresentar um modelo no qual se diferenciam níveis de pensamento algébrico elementar para ajudar na formação dos futuros professores de matemática, porém, sem realizar nenhum estudo com alunos da educação básica.

É com base nessas pesquisas que surgiu o interesse em responder, nesse artigo, a seguinte questão: é possível propor um modelo que indique níveis de desenvolvimento do pensamento algébrico revelado por alunos ao resolverem problemas de partilha?

Resolvemos escolher um tipo de situação - os problemas de partilha de quantidades por alguns motivos. Em primeiro lugar, acreditamos que os alunos podem estar em um ou outro nível dependendo do tipo de situação a ser respondida. Em segundo lugar, os problemas de partilha são, segundo Almeida e Câmara (2014), os mais propostos nos livros didáticos brasileiros para o ensino de equações polinomiais do $1^{\circ}$ grau. E, as pesquisas de Oliveira e Câmara (2011) indicam que alguns alunos utilizam estratégias mais sofisticadas que outros na resolução desse tipo de problema, apontando para possíveis níveis de desenvolvimento. 
DOI: http://dx.doi.org/10.20396/zet.v26i3.8650717

Acreditamos, também, que o modelo proposto nesse artigo poderá contribuir tanto para o trabalho do professor em sala de aula, como pensar sobre a construção de propostas curriculares, pois é fundamental a proposição de currículos que levem em consideração a álgebra como forma de pensar e que desenvolver o pensamento algébrico deve ser o foco do ensino de álgebra, assim como para futuras pesquisas, como as que desejam propor situações que levem o estudante a desenvolver essa forma de pensar, uma vez que o modelo aqui proposto poderá indicar o nível em que o aluno se encontra e se ele avançou ou não.

\section{Problemas de partilha}

Um problema de partilha (PP) se caracteriza por ter uma quantidade total conhecida que é repartida em partes desiguais e desconhecidas (Marchand \& Bednarz, 1999). Podemos visualizar um exemplo desse tipo de problema a seguir:

Alan, Bruno e Carlos têm, juntos, 120 figurinhas. Bruno tem o dobro de figurinhas de Alan e Carlos tem 40 figurinhas a mais que Alan. Quantas figurinhas tem cada um?

Representamos esse problema no esquema a seguir, no qual podemos perceber que para o estudante realizar a conversão do enunciado em linguagem natural para a equação, em linguagem algébrica, é necessário estabelecer relações entre as informações, entre os dados colocados no problema.

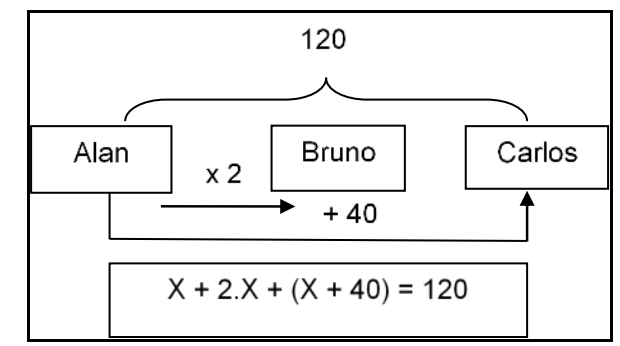

Figura 1 - Estrutura do problema de partilha

Fonte: Elaborado pelos autores

Esse tipo de problema foi estudado por Marchand e Bednarz (1999) que identificaram algumas variáveis ligadas às relações envolvidas que podem influenciar o rendimento dos alunos, que são o número, a natureza e o encadeamento das relações. Em nosso estudo, fixamos o número de relações em duas, variando as outras ${ }^{3}$. A natureza das relações diz respeito às operações entre elas, isto é, a sentença "tem o dobro" é de natureza multiplicativa, já a sentença tem "40 a mais" é de natureza aditiva.

Em relação ao encadeamento das relações, os PP podem ser do tipo fonte, composição ou poço (Marchand \& Bednarz, 1999). No encadeamento tipo fonte, as grandezas são originadas em função de apenas uma grandeza. Quando o encadeamento é do tipo composição, as relações são estabelecidas seguindo uma sequência. Já nos problemas com encadeamento tipo poço, as relações convergem para uma das personagens do problema. No

\footnotetext{
${ }^{3}$ Com a variação das outras relações foi possível elaborar 12 problemas, que podem ser vistos no apêndice.
} 
DOI: http://dx.doi.org/10.20396/zet.v26i3.8650717

apêndice temos os testes utilizados nesse trabalho com uma análise que nos permite perceber, com exemplos, a diferença entre cada tipo de PP.

Pesquisas apontam que o encadeamento das relações desses problemas influencia o rendimento dos alunos. Os PP com encadeamento tipo poço são os considerados mais difíceis de serem resolvidos pelos estudantes, seguidos dos com encadeamento tipo composição. Já os com encadeamento tipo fonte são os considerados mais fáceis (Marchand \& Bednarz, 1999; Oliveira \& Câmara, 2011; Santos Junior, 2013). Esse grau de complexidade dos PP nos possibilitou a proposição de subníveis dentro dos níveis de desenvolvimento do pensamento algébrico proposto pelo modelo aqui apresentado.

\section{Pensamento algébrico}

É possível perceber, a partir das pesquisas de Lins (1992; 1994a; 1994b), Kaput (1999; 2008) e Radford (2006; 2009; 2011), que caracterizar "pensamento algébrico" não é algo simples. Isso ocorre, talvez, pelo fato de o extenso campo em que essa forma de pensar se insere, a álgebra, ter um número grande de objetos de estudo, como equações, inequações, sistemas de equações e de inequações, funções, padrões etc., além de processos algébricos, como inversão e simplificação (Radford, 2006).

Para Lins (1992), pensar algebricamente é uma maneira, entre outras, de produzir significado para a álgebra. Nesse sentido, para esse autor o aluno está pensando algebricamente quando ele consegue construir significado para os objetos algébricos, como as equações e inequações, ideia também defendida por Arcavi (2005).

Kaput (1999, 2008) destaca que o pensamento algébrico é uma atividade exclusivamente humana que surge das generalizações estabelecidas, como resultado de conjecturas sobre dados e relações matemáticas e por meio de uma linguagem cada vez mais formal, usada na argumentação. E, assim como Lins (1992), Kaput defende que o aluno está a pensar algebricamente quando constrói significado para os objetos e a linguagem algébrica.

Já para Radford (2011), o que diferencia o pensamento algébrico do aritmético é que, enquanto nesse último lidamos com quantidades conhecidas, no pensamento algébrico lidamos com quantidades indeterminadas de uma maneira analítica, ou seja, tratamos quantidades desconhecidas (por exemplo, incógnitas ou variáveis) como se fossem conhecidas e realizamos cálculos com elas como fazemos na aritmética, com os valores conhecidos.

Almeida e Câmara (2017), com base nos estudos de Lins (1992, 1994a, 1994b), Kaput (1999, 2008) e Radford (2006, 2009, 2011), além de seus colaboradores, defendem que o pensamento algébrico é, assim como nos colocam Kaput (2008) e Radford (2011), uma ação exclusivamente humana que surge da necessidade de trabalhar com o geral e de construir significado para os objetos e a linguagem algébrica.

Ainda segundo Almeida e Câmara (2017), o pensamento algébrico é revelado nas seguintes características: "estabelecer relações"; "generalizar"; "modelar"; "construir significado" e "operar com o desconhecido". Além disso, eles defendem que no centro 
DOI: http://dx.doi.org/10.20396/zet.v26i3.8650717

dessas características está a capacidade de estabelecer relações, e, subjacentes a ela, porém, não menos importantes, estão as outras. Por conta disso, a primeira característica do pensamento algébrico desenvolvida e revelada por um sujeito é a capacidade de estabelecer relações, seguida pelas demais.

Para entender melhor essa ideia de pensamento algébrico, os autores apresentam o esquema a seguir, que mostra como essas características se comunicam e inter-relacionam entre si.

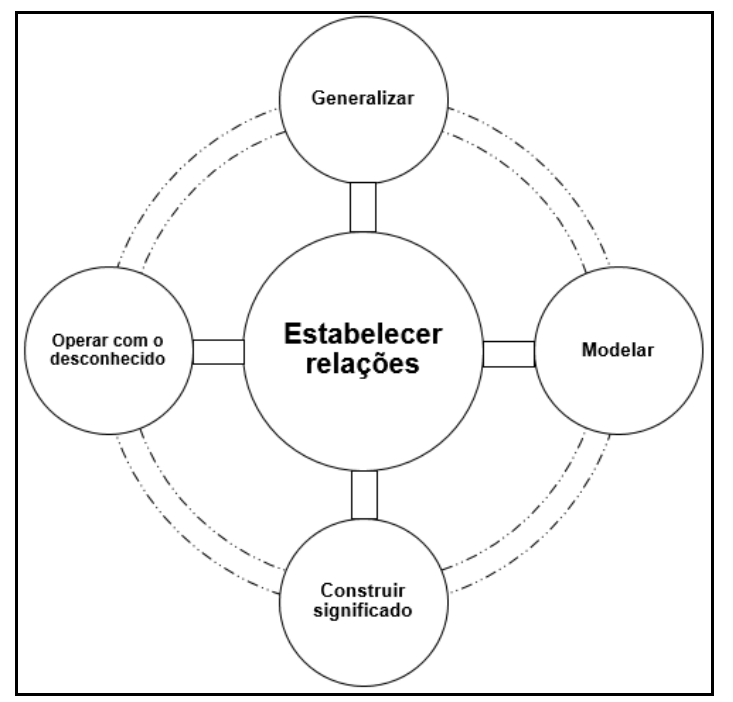

Figura 2 - Esquema das características do pensamento algébrico

Fonte: Almeida e Câmara (2017, p. 54)

Para entender como cada característica se revela na resolução de um problema, iremos utilizar como exemplo o PP a seguir.

Joana, Paulo e Roberto vão repartir 37 balas de modo que Paulo receba 5 balas a mais que Joana e Roberto receba 2 balas a mais que Joana. Quantas balas receberá cada um?

Para um aluno iniciar a resolução de um problema de estrutura algébrica ele tem que estabelecer as relações entre as informações do enunciado. Por exemplo, no problema supracitado, o aluno inicia a resolução estabelecendo as relações existentes entre as partes (a quantidade de balas que cada personagem irá receber) e o todo (o total de balas), revelando, segundo Almeida e Câmara (2017), a característica central dessa forma de pensar, a "capacidade de estabelecer relações".

Após estabelecer as relações, o aluno tende a construir um modelo matemático para representar o problema apresentado em linguagem natural. E, dependendo do nível de desenvolvimento do pensamento algébrico em que esse aluno se encontra, esse modelo 
matemático terá uma linguagem algébrica mais ou menos formal ${ }^{4}$ (Kaput, 1999, 2008; Radford, 2009, 2011). É nesse momento que ele revela, segundo Almeida e Câmara (2017), outra característica do pensamento algébrico, que é a "capacidade de modelar", ou seja, de construir um modelo matemático que revele as relações propostas nas informações do enunciado do problema, chegando, por exemplo, à equação " $X+X+5+X+7=37$ ".

Concomitante a esse processo de modelar, geralmente surge outra característica do pensar algebricamente, a "capacidade de generalizar", tendo em vista que o aluno representa, após a conversão do problema, as quantidades de uma forma geral. No exemplo trazido anteriormente, a quantidade de balas que cada personagem irá receber é representada, na equação, de uma forma geral, isto é, o modelo apresenta uma síntese das relações existentes entre as quantidades de balas que cada personagem irá receber e essas relações são descritas em uma linguagem genuinamente algébrica, em que o $\mathrm{X}$ pode representar um valor qualquer, valor esse que, no problema em questão, é descoberto após a resolução da equação (Radford, 2009, 2011).

No processo de resolução da equação para se descobrir o valor de $\mathrm{X}$, o aluno mobiliza, de acordo com Almeida e Câmara (2017), a "capacidade de operar com o desconhecido como se fosse conhecido", ou seja, de forma analítica (Lins, 1992, 1994a, 1994b; Radford, 2006, 2009, 2011). Essa característica do pensamento algébrico é revelada quando o aluno manipula o desconhecido, o "X" no caso, segundo as leis da aritmética em relação à igualdade, em que são realizadas algumas operações na equação inicial com o objetivo de gerar equações equivalentes, até se chegar ao valor de " $\mathrm{X}$ ".

Por fim, porém não menos importante, Almeida e Câmara (2017) destacam que ao mesmo tempo em que o aluno mobiliza as características supracitadas do pensamento algébrico, ou algumas delas, ele também está lidando com a quinta e última característica dessa forma de pensar, a "capacidade de construir significado para a linguagem e os objetos algébrico” (Lins, 1992, 1994a, 1994b; Kaput, 1999, 2008; Arcavi, 2005; Radford, 2009).

Isso acontece quando o aluno compreende o problema de partilha como uma equação polinomial do $1^{\circ}$ grau, ou seja, que existe uma relação de igualdade entre quantidades. No caso do exemplo, a soma das quantidades de balas que cada personagem irá receber é igual ao total de balas e representa essa relação de igualdade por meio de um modelo matemático, utilizando uma linguagem algébrica formal.

Ressaltamos que apesar de apresentar as quatro características subjacentes à central seguindo uma sequência, "isso não significa que elas sejam reveladas pelo sujeito nessa ordem, muito pelo contrário, acreditamos que elas surgem e se desenvolvem de forma concomitante, e que o desenvolvimento de uma dessas características leva, consequentemente, ao desenvolvimento de outras" (Almeida \& Câmara, 2017, p. 58).

\footnotetext{
${ }^{4}$ Para Almeida e Câmara (2017), a linguagem algébrica formal é a utilizada tradicionalmente no ambiente escolar, ou seja, formada por sinais essencialmente algébricos, como letras, números, sinais das operações aritméticas, sinal de igualdade, dentre outros.
} 


\section{Método}

Para se chegar ao modelo aqui apresentado, foi construída uma versão preliminar a partir de uma análise da produção escrita de 342 alunos do $6^{\circ}$ ano do ensino fundamental na resolução de um teste ${ }^{5}$ composto por $6 \mathrm{PP}$ cada.

Após essa fase, aplicamos o mesmo questionário a 343 alunos dos anos finais do ensino fundamental de duas escolas da cidade do Recife, sendo 72 alunos do $6^{\circ}$ ano, 83 do $7^{\circ}$ ano, 93 do $8^{\circ}$ ano e 95 do $9^{\circ}$ ano. Para esse artigo, trazemos a análise da produção escrita e de uma entrevista de explicitação realizada por 8 alunos. A escolha desses alunos se deu a partir dos níveis de desenvolvimento do pensamento algébrico em que eles se encontravam em relação à versão preliminar do modelo.

Portanto, diante do critério adotado, decidimos entrevistar dois alunos por nível, sendo um que ainda não tinha iniciado o estudo formal de álgebra ( $6^{\circ}$ ou $7^{\circ}$ ano) e outro que já tinha iniciado ( $8^{\circ}$ ou $9^{\circ}$ ano), totalizando oito alunos, uma vez que a versão preliminar indicava a possibilidade de quatro níveis. No quadro a seguir encontramos os nomes fictícios desses alunos, o ano de escolaridade e o nível de desenvolvimento do pensamento algébrico em que eles se encontram.

Tabela 1 - nomes fictícios dos entrevistados

\begin{tabular}{|c|c|c|}
\hline Nome fictício & Ano de escolaridade & Nível \\
\hline Ana & $7^{\circ}$ ano & \multirow{2}{*}{0} \\
\hline Isabel & $8^{\circ}$ ano & \\
\hline Caio & $6^{\circ}$ ano & \multirow{2}{*}{1} \\
\hline Carol & $9^{\circ}$ ano & \\
\hline Paula & $6^{\circ}$ ano & \multirow{2}{*}{2} \\
\hline Polly & $9^{\circ}$ ano & \\
\hline Júlia & $7^{\circ}$ ano & \multirow{2}{*}{3} \\
\hline Carlos & $9^{\circ}$ ano & \\
\hline
\end{tabular}

Fonte: Elaborado pelos autores

Utilizamos o método da entrevista de explicitação, desenvolvido por Vermersch (1994), por acreditar que deveríamos ir além da resposta registrada no papel, uma vez que queríamos identificar características de pensamento algébrico, e essas características são essencialmente mentais. Portanto, não podemos ficar apenas na análise dos registros escritos, pois eles talvez não nos revelem com clareza o que o aluno estaria pensando no momento em que estava resolvendo o problema.

As entrevistas foram gravadas em áudio e realizadas individualmente na biblioteca da escola, aproximadamente uma semana após o aluno ter respondido o teste. De início foi explicado ao aluno o objetivo da entrevista e que ela seria gravada em áudio, e em seguida o

\footnotetext{
${ }^{5}$ Esses testes foram cedidos por Oliveira e Câmara (2011), de sua pesquisa que aplicou dois testes diferentes (A e B), cada um com 6 problemas de partilha, porém cada aluno respondeu a apenas um teste. Em anexo temos esses testes com as estruturas de cada PP.
} 
DOI: http://dx.doi.org/10.20396/zet.v26i3.8650717

pesquisador/entrevistador perguntava se ele concordava em participar. Nenhum aluno se negou em colaborar com essa fase da pesquisa. Todas as entrevistas foram transcritas.

\section{O modelo}

Para a proposição do modelo iremos assumir como base para a definição dos níveis a estratégia adotada pelo aluno, e para os subníveis o grau de complexidade dos PP. Para nomear os níveis de pensamento algébrico, tomamos emprestada a nomenclatura sugerida por Godino et al. (2014).

\section{Nível 0 - ausência de pensamento algébrico}

Os alunos que se encontram nesse nível não conseguem mobilizar, quando se deparam com um PP com duas relações, nenhuma característica do pensamento algébrico. Isso ocorre pelo fato deles não conseguirem estabelecer as relações existentes entre as quantidades de cada personagem e o total. Por conta disso, os alunos que se encontram no nível 0 deixam o problema sem resposta, ou adotam alguma estratégia que leva à resposta errada.

Uma das estratégias adotadas pelos alunos que se encontram nesse nível é "dividir por 3", dividindo o total do problema para as três incógnitas do enunciado, como se a partilha desse fosse em partes iguais, como em um problema aritmético (Oliveira \& Câmara, 2011). Temos, na figura 4 a seguir, a resposta da aluna Isabel à Q5b ${ }^{6}$.

Q5b. Ana, Júlia e Maria têm, juntas, 180 selos. Júlia tem um terço dos selos de Ana e a metade dos selos de Maria. Quantos selos têm cada uma?

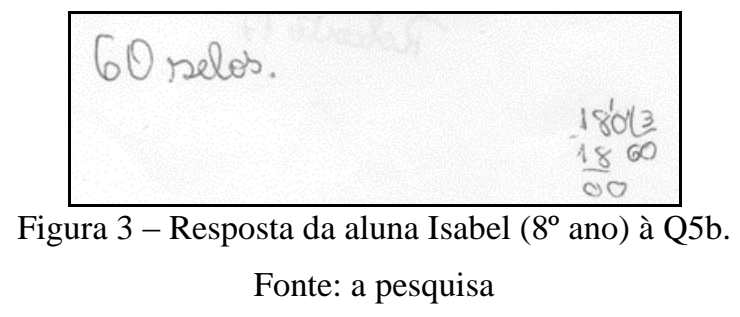

Percebemos que a aluna não considera, quando está a resolver o problema, as relações existentes entre as personagens do enunciado, ou seja, a condição "Júlia tem um terço dos selos de Ana e a metade dos selos de Maria" não é considerada pela aluna. Na verdade, ela responde o problema como se a divisão fosse em partes iguais, em que cada personagem teria a mesma quantidade de selos, como podemos verificar nas explicações a seguir.

P: Como foi que você fez esse problema?

Isabel: Eu peguei esse aqui (apontando para os 180) e dividi por três, que deu 60. Então cada um tem 60.

P: Por que 180 dividido por 3?

\footnotetext{
${ }^{6}$ Iremos adotar nas nossas análises as representações Q1a, Q2a, ..., Q6a para indicar as questões do teste A e Q1b, Q2b, ..., Q6b para indicar as questões do teste B.
} 
DOI: http://dx.doi.org/10.20396/zet.v26i3.8650717

Isabel: Porque era três pessoas que tinham selos.

(Diálogo entre entrevistador e aluna, 2016)

Portanto, é possível perceber que, mesmo questionada algumas vezes sobre como chegou à resposta, Isabel sempre respondia que era porque tinham três pessoas, "porque são 180 selos para três pessoas, então 180 dividido por 3 dá 60 ". Ou seja, ela não considera as condições propostas no enunciado do problema, demonstrando compreendê-lo como um simples problema de estrutura aritmética, em que é solicitada a divisão de 180 selos para três pessoas.

Outra estratégia adotada por alunos que não conseguem estabelecer as relações necessárias na resolução de um problema desse tipo é a estratégia "cálculo qualquer", em que "eles buscam efetuar uma conta qualquer na tentativa de encontrar uma solução" (Oliveira \& Câmara, 2011, p. 8). Podemos visualizar essa estratégia na resposta de Ana à Q2b a seguir.

Q2b. Joana, Paulo e Roberto vão repartir 37 balas de modo que Paulo receba 5 balas a mais que Joana e Roberto receba 2 balas a mais que Joana. Quantas balas receberá cada um?

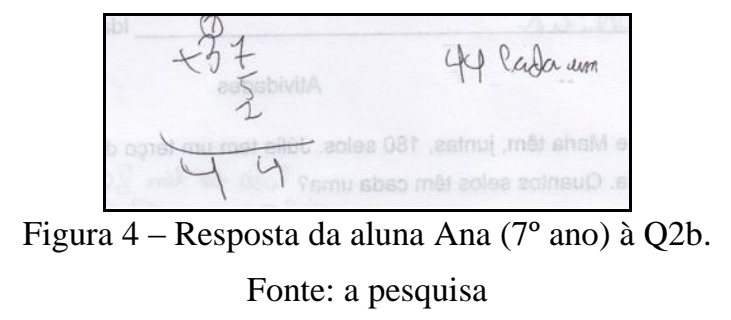

É possível verificar que Ana chega, de forma equivocada, à resposta do problema somando os valores que se encontram no enunciado, e, assim como Isabel, não considera as condições do problema. Além disso, em suas explicações, ela afirma que realizou essa soma apenas pelo fato desses serem os valores que se encontravam no enunciado, como podemos observar a seguir.

P: Como você chegou à resposta desse problema?

Ana: Eu coloquei 37 mais 5 mais 2, e somei 7 mais 5 mais 2, que deu 14. Eu coloquei o 4 aqui (apontando para o 4 abaixo do 2 nos cálculos) e o 1 aqui (apontando para o 1 sobre o 3 nos cálculos), e somei 3 mais 1, que deu 4. Então deu no total 44.

P: Então cada um vai receber 44 balas?

Ana: É.

P: Mas por que dessa soma?

Ana: Porque aqui tem 37, aqui tem 5 e aqui tem 2 (apontando para o problema).

(Diálogo entre entrevistador e aluna, 2016)

Nesse caso, Ana retirou os valores que se encontravam no enunciado do problema e realizou uma operação, no caso uma soma, para chegar à resposta do problema. Portanto, 
assim como Isabel, Ana entende o problema de partilha como sendo de estrutura aritmética, em que é necessário para se chegar à resposta realizar algumas operações com os valores conhecidos do enunciado.

Nesse sentido, concluímos que o nível 0 do modelo aqui proposto é composto pelos alunos que não conseguem se apropriar do significado do problema em questão, ou seja, não conseguem estabelecer as relações existentes entre as incógnitas e o total em um PP com duas relações. Entretanto, isso não significa que um aluno que se encontra nesse nível não mobiliza, em nenhum momento, alguma característica do pensamento algébrico. Ele pode mobilizar algumas das características dessa forma de pensar quando se depara com outras situações como, por exemplo, as de generalização de sequências. Isso pode acontecer caso ele tenha tido mais experiências com situações de ensino que promovam a capacidade de realizar generalizações de padrões, ao invés de problemas de partilha (Radford, 2009).

\section{Nível 1 - pensamento algébrico incipiente}

O aluno que se encontra no nível 1 adota, como estratégia de base para a resolução dos PP, a estratégia atribuir valores, entendendo a incógnita como um espaço vazio que deve ser preenchido com valores particulares e conhecidos (Radford, 2009), como podemos verificar na explicação que o aluno Caio coloca ao lado da resposta à Q1b.

Q1b. Frederico, Rogério e Lúcia têm, juntos, 55 revistas em quadrinhos. Rogério tem o dobro de revistas de Frederico e Lúcia tem 15 revistas a mais que Frederico. Quantas revistas em quadrinhos têm cada um?

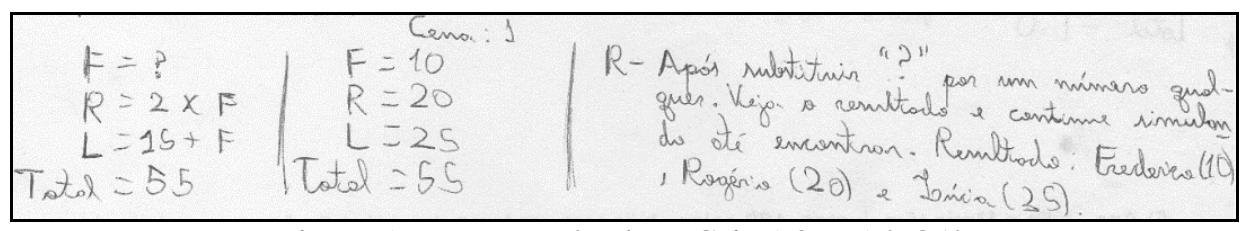

Figura 5 - Resposta do aluno Caio (6 $6^{\circ}$ ano) à Q1b

Fonte: a pesquisa

Percebemos, portanto, que o aluno coloca em seu modelo que a quantidade de revistas de Frederico é igual ao sinal de interrogação para indicar que é um valor desconhecido, e que foi substituído, no que ele chama de cena 1, por 10, que é a quantidade correta de revista de Frederico. Porém, na explicação que ele coloca ao lado ele indica que no momento da resolução do problema a interrogação pode ser substituída por um valor qualquer até chegar à resposta do problema. Esse fato também é revelado quando o pesquisador pede para ele explicar como chegou à resposta do problema.

P: Caio você lembra se começou com o 10 já, ou você tentou outros valores?

Caio: Pois é, eu dei sorte nessa hora, porque eu pensei, vou colocar o 10 porque é o valor que não vai dá números com vírgula, então eu coloquei o 10 e deu certo.

P: Mas poderia ser outro número? 
DOI: http://dx.doi.org/10.20396/zet.v26i3.8650717

Caio: Poderia.

(Diálogo entre entrevistador e aluno, 2016)

Portanto, o aluno não chega à resposta na primeira tentativa porque já sabia que 10 era a quantidade de revista de Frederico, mas porque o primeiro valor escolhido foi o correto. Como ele mesmo diz, poderia começar com outro valor.

Esse fato de ter a incógnita como um espaço vazio que deve ser preenchido por um valor conhecido, típico de um aluno que se encontra no nível 1, também é percebido na resposta de Carol, como podemos verificar a seguir.

Q6b. Sílvia, Pedro e Carlos querem dividir 70 figurinhas entre eles de modo que Sílvia receba 30 figurinhas a menos que Pedro e a metade da quantidade de figurinhas de Carlos. Quantas figurinhas cada um vai receber?

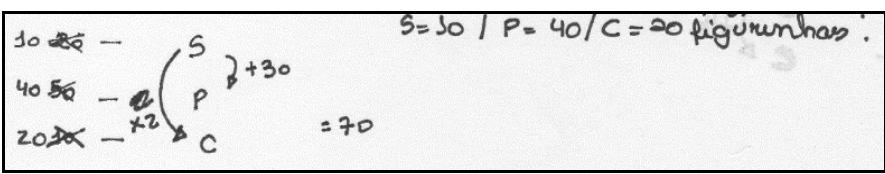

Figura 6 - Resposta da aluna Carol ( $9^{\circ}$ ano) à Q6b

Fonte: a pesquisa

Quando observamos a resposta da aluna Carol, percebemos que ela inicia a resposta substituindo o número de figurinhas de Sílvia por 20, porém, percebe que a resposta não é a correta e troca o valor por 10, chegando ao resultado final. Esse fato é revelado também no extrato a seguir da entrevista realizada com a aluna.

P: Me explica como foi que você chegou nesses valores aqui?

Carol: Também por estimativa.

P: Vê, você tenta com 20 , e deu 80 , é isso que você está falando?

Carol: Isso.

P: Então, você diminui a quantidade para 10 para ver se dá 70 ?

Carol: Foi.

P: Não poderia aumentar esse valor?

Carol: Não. Se fosse maior sairia ainda mais dos 70.

(Diálogo entre entrevistador e aluna, 2016)

Percebemos, no trecho da entrevista de Carol, que as tentativas de chegar às respostas corretas, a partir da primeira tentativa, não são feitas ao acaso. Por exemplo, na primeira tentativa, Carol atribui 20 ao número de figurinhas de Sílvia, e, após realizar seus cálculos percebe que o valor encontrado é maior que o desejável, partindo para um valor menor, escolhendo agora o 10. E, questionada se poderia escolher um valor maior que 20 para a segunda tentativa, ela responde que não. "Se fosse maior sairia ainda mais dos 70", ou seja, daria um número ainda maior que 70 , demonstrando, portanto, a mobilização da característica central do pensamento algébrico, a capacidade de estabelecer relações.

Assim como Carol, a resposta de Caio à Q1b (figura 6) indica que ele inicia a resolução do problema estabelecendo as relações entre as informações do enunciado, ou seja, 
DOI: http://dx.doi.org/10.20396/zet.v26i3.8650717

entre as quantidades de revistas de cada personagem e o total de revistas, o que é necessário para iniciar a resolução de um problema de estrutura algébrica (Marchand \& Bednarz, 1999; Ruiz, Bosch \& Gascón, 2010; Oliveira \& Câmara, 2011). Isso é confirmado no extrato de entrevista a seguir.

P: Caio isso daqui é o quê (apontando para o modelo do aluno)?

Caio: $O R$ é Rogério, e Rogério é duas vezes o valor de Frederico. Então, vou fazendo essas relações e tentando achar.

\section{P: E Lúcia é?}

Caio: Lúcia é o valor de Frederico mais 15.

P: Certo. Então você foi substituindo o valor de Frederico até chegar no total, é isso?

Caio: Sim.

P: E qual era o total?

Caio: 55. Porque os três têm, juntos, 55 revistas em quadrinhos.

(Diálogo entre entrevistador e aluno, 2016)

Além disso, Caio também demonstra, tanto em sua resposta escrita como em sua entrevista, que seu modelo representa as relações existentes entre as quantidades de revistas de cada personagem e o total de revistas, revelando ter iniciado a capacidade de modelar e de entender o problema como uma relação de igualdade entre quantidade, ou seja, compreende o problema como uma equação polinomial do $1^{\circ}$ grau, mesmo não a representando da forma algébrica esperada.

$\mathrm{Na}$ entrevista, Caio também revela ter compreensão do que cada símbolo de seu modelo significa, reafirmando a capacidade de construir significado para a linguagem algébrica utilizada, mesmo que essa linguagem ainda seja uma linguagem sincopada.

A resposta da aluna Carol à Q6b também revela a mobilização da capacidade de estabelecer relações, de modelar e de construir significado, tendo em vista que ela, assim como Caio, inicia a resolução do problema estabelecendo as relações e representando-as em um modelo, ou seja, converte o problema para um registro em linguagem sincopada, e, esse modelo indica que a aluna compreendeu o problema como uma equação, mesmo não representando a equação da forma esperada. Também é possível confirmar isso no extrato de entrevista a seguir.

P: Me explica esses esquemas que você fez?

Carol: Isso aqui é Silvia, Pedro e Carlos (apontando para S, P e C), e isso aqui é o total de figurinhas (apontando para o " $=70 "$ ).

P: Por isso você colocou igual a 70 ?

Carol: Foi. Então, de Silvia para Pedro, Sílvia receberia 30 figurinhas a menos que Pedro, então eu sabia que, vamos supor, se Sílvia tem X, X mais 30 seria o valor de Pedro.

P: Por que ela recebe 30 a menos que Pedro, então Pedro receberia 30 a mais que ela? 
DOI: http://dx.doi.org/10.20396/zet.v26i3.8650717

Carol: Isso. Então eu fui fazendo isso também, e a metade de Carlos, então se ela tinha metade, então X vezes 2 seria igual a Carlos.

(Diálogo entre entrevistador e aluna, 2016)

Portanto, foi possível comprovar, a partir dos registros escritos dos participantes e das entrevistas, que o nível 1 - pensamento algébrico insipiente - é formado pelos alunos que adotam a estratégia atribuir valores na resolução dos problemas de partilha com duas relações, e que a adoção dessa estratégia revela a mobilização de três das cinco características que compõem o pensamento algébrico, a capacidade de estabelecer relações, a capacidade de modelar e a capacidade de construir significado para a linguagem e os objetos algébricos.

Além disso, foi identificado que o grau de complexidade dos PP com duas relações possibilita a proposição de subníveis a partir do nível 1. No subnível 1A estão os alunos que conseguem, mobilizando a estratégia atribuir valores, responder os problemas de partilha considerados mais fáceis, que são os com encadeamento das relações tipo fonte (Oliveira \& Câmara, 2011; Santos Junior, 2013).

No subnível 1B encontram-se os alunos que conseguem responder os problemas de partilha que têm um grau de complexidade baixo e médio, que são os com encadeamento das relações tipo fonte e composição. Já no subnível 1C estão os alunos que respondem aos PP independente do encadeamento das relações (fonte, composição ou poço).

\section{Nível 2 - pensamento algébrico intermediário}

A diferença entre os alunos que se encontram no nível 1 e os que se encontram no nível 2 é que nesse último o modelo matemático se aproxima mais do modelo esperado para o problema, ou seja, a equação polinomial do $1^{\circ}$ grau. A estratégia adotada por eles já é denominada por Oliveira e Câmara (2011) de algébrica, porém, com um registro sincopado, ou seja, o aluno ainda não consegue chegar no registro da equação da forma que é esperado em um ambiente escolar.

Por pensar o problema já como uma equação, o aluno desse nível revela, além das três características já mobilizadas pelos alunos que se encontram no nível anterior, uma quarta característica do pensamento algébrico, a capacidade de generalizar, uma vez que a indeterminação, isto é, a incógnita, já aparece de forma explícita no discurso do aluno (Radford, 2009), como podemos perceber na resposta da aluna Paula à Q3b.

Q3b. Três times de basquete participam da final do campeonato fazendo, juntos, 240 pontos. $O$ time $B$ vez o dobro de pontos do time A e o time $C$ fez 40 pontos a mais que o time B. Quantos pontos fez cada time?

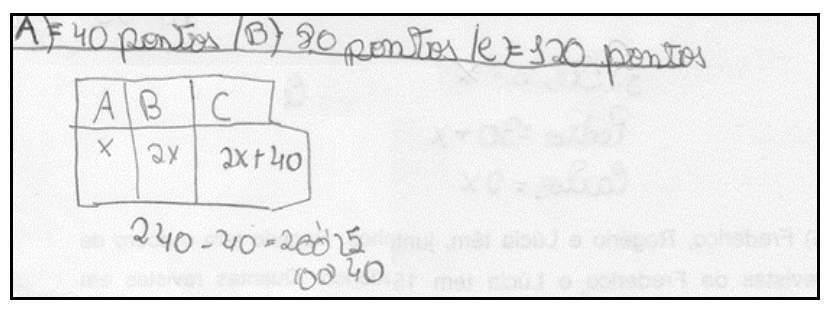


DOI: http://dx.doi.org/10.20396/zet.v26i3.8650717

Figura 7 - Resposta da aluna Paula (6 $6^{\circ}$ ano) à Q3b

Fonte: a pesquisa

Podemos perceber que Paula consegue identificar as relações entre as informações do problema e as converte para um modelo matemático, em que a quantidade de pontos do time A é representada por $\mathrm{X}$, a do time $\mathrm{B}$ por $2 \mathrm{X}$, já que ele fez o dobro de pontos do time $\mathrm{A}$, e a do time $\mathrm{C}$ por $2 \mathrm{X}+40$, uma vez que ele fez 40 pontos a mais que o time $\mathrm{B}$. Apesar dela não representar no modelo que os três times fizeram, juntos, 240 pontos, na entrevista ela revela saber dessa informação e a utiliza, como podemos verificar no extrato a seguir.

P: Me explica como você chegou à resposta desse problema?

Paula: Ele fala que eles fizeram juntos 240 pontos, ou seja, os 3 iguais a 240, e o time $B$ fez o dobro de pontos do time A, e o time $C$ fez 40 pontos a mais que o time B. Então, como o time A é o menor, podemos nos basear nele para fazer as coisas, ou seja, igual a X. A é igual a X, o B é igual a quanto? A $2 X$, que éo dobro de $X$, e o C é igual a $2 X$, que é o $B$, mais 40.

$P$ : E depois como foi que você chegou à resposta?

Paula: Eu tive que dividir. Então, eu peguei 240 e tirei esse 40 (apontando para os 40 a mais do time C) porque tinha somado para dá os 240. Por que isso é 240 (apontando para o modelo com os três times) e tirei (se referindo aos 40) e deu 200, para dividir por quanto X, um, dois, três, quatro, cinco X (apontando para a quantidade de $X$ de cada time representada no modelo), ou seja, 200 dividido por 5, que dá 40. Então, esse aqui é 40 (apontando para o time A no modelo), esse aqui é 80 (apontando para o time B), que é $2 X, 2$ vezes 40, e esse aqui (apontando para o time C) é 80 mais 40, que fica 120.

(Diálogo entre entrevistador e aluna, 2016)

Além disso, é possível verificar também que Paula realiza as operações aritméticas $(240-40=200$ e $200 / 5=40)$ como se estivesse resolvendo uma equação, como podemos perceber em suas explicações.

Outros alunos, que adotam a estratégia algébrico com registro sincopado, chegam na equação mentalmente, e, o modelo utilizado por eles para representar a conversão do problema não é composto pelos símbolos essencialmente algébrico, como o modelo construído por Paula. Em alguns casos, o aluno não utiliza letras para representar as personagens do problema, mas, sim, os próprios nomes como podemos observar na resposta de Polly.

Q1b. Frederico, Rogério e Lúcia têm, juntos, 55 revistas em quadrinhos. Rogério tem o dobro de revistas de Frederico e Lúcia tem 15 revistas a mais que Frederico. Quantas revistas têm cada um?

\begin{tabular}{|c|c|c|c|}
\hline $\begin{array}{l}\text { TOTAL } \rightarrow 55 \\
\text { ROCER } \\
\text { WCIO } \rightarrow \text { FRESERIO } \rightarrow 2\end{array}$ & $\begin{aligned} & 55 \\
-\frac{15}{40} & \frac{4}{10}\end{aligned}$ & $\begin{array}{l}\text { ROSERIO }=20 \text { QUADRINHOS } \\
\text { FRESERICO }=10 \text { QUADRINHOS } \\
\text { LÚCIA }=25 \text { QUADRINHCS }\end{array}$ & RESPOSTA \\
\hline
\end{tabular}


DOI: http://dx.doi.org/10.20396/zet.v26i3.8650717

Figura 8 - Resposta da aluna Polly ( $9^{\circ}$ ano) à Q1b

Fonte: a pesquisa

No caso da resposta de Polly à Q1b, ela inicia indicando, por meio da expressão "Total $\rightarrow 55$ ", que o total de revistas das três personagens é igual a 55. Em seguida, ela converte a expressão "Rogério tem o dobro de revistas de Frederico" em "Rogério $\rightarrow$ Frederico · 2", e "Lúcia tem 15 revistas a mais que Frederico" em "Lúcia $\rightarrow$ Frederico +15 ", ou seja, se vale de uma linguagem mais concisa - que na história da matemática, e em especial da álgebra, é denominada de sincopada - para representar as relações do problema, construindo, portanto, um modelo matemático, porém, não com a linguagem usualmente utilizada na álgebra atual, mas, uma linguagem que também foi utilizada, em um determinado estágio de desenvolvimento da álgebra, como a mais adequada para resolver problemas de estrutura algébrica (Araújo, 2008; Radford, 2011).

Após identificar as relações, Polly resolve a equação, mesmo que, assim como Paula, essa equação não esteja da forma que tradicionalmente é trabalhada no ambiente escolar. As etapas dessa resolução são melhor compreendidas nas explicações da aluna a seguir.

P: Me explica como você chegou à resposta desse problema?

Polly: Eu subtraí a quantidade que tinha a mais e depois eu dividi pela quantidade de pessoas que tinha.

P: Mas nesse caso tinha três pessoas!

Polly: Isso. Mas tinha uma pessoa que tinha o dobro, então, tinha que ser uma quantidade que conseguisse, tipo, tinha três pessoas, mas uma pessoa tinha o dobro de revistas de Frederico. Rogério tinha o dobro de Frederico, então, teoricamente seriam quatro quantidades. Por isso dividi por 4.

P: Então, você tira os 15, que é o que Lúcia tem a mais?

Polly: Lúcia tem a mais que Frederico.

P: Então você tirou esse 15 para ficar em quantidades iguais para cada um?

Polly: Sim.

P: E quando você dividiu por 4 você achou a quantidade de quem?

Polly: Eu achei a quantidade de Frederico, que é a pessoa que Rogério tem o dobro e Lúcia tem mais 15. Ele seria meio que o único que teria uma quantidade certinha. Então, Frederico teria 10, Rogério teria duas vezes Frederico, e Lúcia teria Frederico mais 15, como Frederico teria 10, Rogéria teria 20 e Lúcia teria 25.

(Diálogo entre entrevistador e aluna, 2016)

Portanto, percebemos, nas explicações de Polly, que ela utiliza basicamente as mesmas etapas de resolução da equação tradicionalmente encontradas após a conversão do problema.

Portanto, além das características do pensamento algébrico já mobilizadas pelos alunos que se encontram no nível 1, isto é, a capacidade de estabelecer relações, a capacidade de modelar e a capacidade de construir significado para os objetos e a linguagem algébrica, 
DOI: http://dx.doi.org/10.20396/zet.v26i3.8650717

os alunos que se encontram no nível 2 mobilizam mais uma, a capacidade de generalizar, uma vez que o desconhecido, a incógnita, já faz parte de seus discursos (Kaput, 2008; Radford, 2009).

A partir da análise da produção escrita dos participantes dessa fase da pesquisa, foi possível, assim como para os níveis 1 e 3 , a proposição de três subníveis dentro do nível 2. O subnível 2A é composto pelos alunos que, adotando a estratégia algébrica com registro sincopado, conseguem responder a apenas os problemas de partilha de duas relações com o encadeamento das relações tipo fonte. Já o subnível 2B é formado pelos alunos que conseguem, com essa estratégia, resolver os problemas de partilha com encadeamento das relações tipo fonte e composição, e, no $3 \mathrm{C}$ estão os alunos que com essa estratégia conseguem responder os problemas de partilha independente do encadeamento das relações.

\section{Nível 3 - pensamento algébrico consolidado}

No último nível de nosso modelo, os alunos conseguem, de forma consolidada, mobilizar todas as cinco características dessa forma de pensar, isto é, além das quatro mobilizadas pelos alunos que se encontram no nível 2 (capacidade de estabelecer relações; capacidade de modelar; capacidade de generalizar; e capacidade de construir significado), os alunos que se encontram no nível 3 mobilizam a última característica, a capacidade de operar com o desconhecido como se fosse conhecido, ou seja, de forma analítica.

Isso é possível verificar na resposta de Júlia à Q3b.

Q3b. Três times de basquete participam da final do campeonato fazendo, juntos, 240 pontos. O time $B$ fez o dobro de pontos do time A e o time $C$ fez 40 pontos a mais que o time B. Quantos pontos fez cada time?

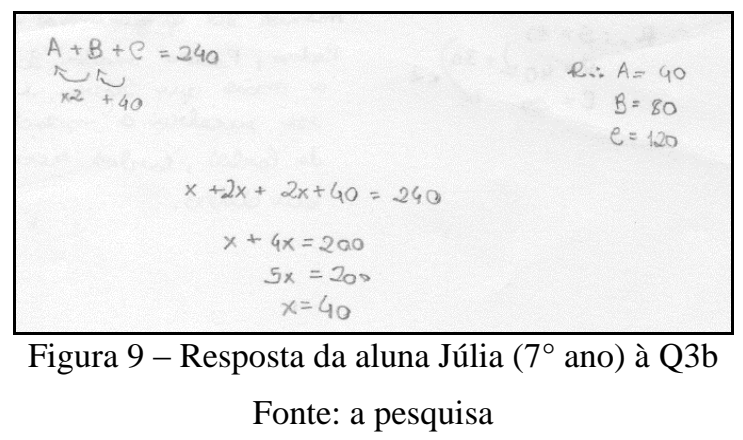

É possível perceber que Júlia converte o problema em dois modelos. Inicialmente ela utiliza as letras de cada time para indicar que a soma dos pontos que eles fizeram é igual a 240 , por isso a equação " $\mathrm{A}+\mathrm{B}+\mathrm{C}=240$ ”. E, para indicar as relações existentes entre a quantidade de pontos que cada time fez ela se vale de setas, sinais de operações aritméticas e números. Por exemplo, ela utiliza $(\leftarrow)$ indo de B para A para indicar que o time B fez o dobro de pontos do time A e $(\overleftarrow{+40})$ indo de $\mathrm{C}$ para B para indicar que o time $\mathrm{C}$ fez 40 pontos a mais que o time $B$. 
DOI: http://dx.doi.org/10.20396/zet.v26i3.8650717

$\mathrm{Na}$ segunda etapa da resolução, Júlia transforma o modelo inicial no modelo tradicionalmente esperado em um ambiente escolar, ou seja, em uma equação polinomial do $1^{\circ}$ grau, no qual as incógnitas são representadas pela letra " $X$ ". No segundo modelo, diferente do primeiro, Júlia já indica as relações existentes entre a quantidade de pontos de cada time na própria equação, em que o " $\mathrm{X}$ " indica a quantidade de pontos do time $\mathrm{A}$, o " $2 \mathrm{X}$ " indica a quantidade de pontos do time $\mathrm{B}$, uma vez que ele fez o dobro de pontos do time $\mathrm{A}$, e o " $2 \mathrm{X}+$ 40 " indica a quantidade de pontos do time $\mathrm{C}$, já que ele fez 40 pontos a mais que o time $\mathrm{B}$. Essas inferências são comprovadas nas explicações de Júlia a seguir.

P: Me explica como você fez esse.

Júlia: $O$ time $B$ fez o dobro de pontos do time A (apontando, no modelo inicial, para $(\leftarrow)$ ), e o time $C$ fez 40 pontos a mais que o time $B$ (apontando para $\left(\longleftarrow_{+40}\right)$ ).Então, o A vai ser $X$, mais $2 X$, que seria $X$ vezes 2 , que é o $B$, porque o $B$ é o dobro do $A$, mais $2 X$, que seria o $B$, mais 40, e essa equação seria o $C$ (chama $2 X+40$ de equação), que é igual a 240. Então, $X$ mais $2 X$ mais $2 X$ mais 40 é igual 240. Eu diminuí 40 dos dois lados, e ficou X mais $4 X$, porque eu juntei os $2 X$ com os $2 X$, que fica igual a 200. E depois eu somei $X$, que ficou $5 X$ igual a 200. X é igual a 40, porque eu dividi 5 dos dois lados.

P: Certo. E depois, você fez como?

Júlia: O time A ficou com 40, o time B ficou com o dobro do time A, que é 80, e o time $C$ ficou com mais 40 vezes 2, que seria 120.

(Diálogo entre entrevistador e aluna, 2016)

Percebemos, portanto, que Júlia já demonstra mobilizar as cinco características que formam o pensamento algébrico. A capacidade de estabelecer relações, de modelar, de generalizar e de construir significado já são reveladas quando ela inicia a resolução do problema. Isso porque o modelo utilizado por ela após a conversão do problema indica que ela percebeu, de forma clara, as relações existentes entre a quantidade de pontos que cada time fez e o total de pontos, representando essas relações em um modelo matemático apropriado e esperado em um ambiente escolar, em que a incógnita aparece claramente, revelando a capacidade de generalizar. Além disso, ela demonstra que entendeu o problema de partilha como uma relação de igualdade entre quantidades, ou seja, como uma equação, além de entender o que cada símbolo utilizado no modelo representa, revelando que a capacidade de construir significado para o objeto algébrico em jogo e para a linguagem algébrica utilizada está bem desenvolvida.

Por fim, Júlia revela que a capacidade de operar com o desconhecido como se fosse conhecido, característica do pensamento algébrico defendida por vários pesquisadores (Lins, 1992, 1994a, 1994b; Kaput, 1999, 2008; Radford, 2006; 2009), está bem desenvolvida, uma vez que ela manipula, na resolução da equação, a incógnita, o "X", de acordo com as regras da aritmética em relação a uma igualdade, em que são realizadas operações na equação inicial com o intuito de gerar equações equivalentes até chegar no valor de " $\mathrm{X}$ ". 
DOI: http://dx.doi.org/10.20396/zet.v26i3.8650717

Isso é possível verificar no registro escrito de Júlia em que ela realiza, de forma mental, as operações para se chegar às equações equivalentes até encontrar o valor da incógnita; a comprovação de que essas operações foram realizadas de acordo com as regras supracitadas são obtidas a partir das explicações de Júlia, quando, por exemplo, ela diz "eu diminuí 40 dos dois lados, e ficou $\mathrm{X}$ mais $4 \mathrm{X}$, porque eu juntei os $2 \mathrm{X}$ com os $2 \mathrm{X}$, que fica igual a 200. E depois eu somei X, que ficou $5 X$ igual a 200. Então, $X$ é igual a 40, porque eu dividi 5 dos dois lados".

Outros alunos também revelam estar em um nível consolidado do pensamento algébrico, porém, seus registros escritos não são tão organizados como os de Júlia. Entretanto, ressaltamos que não é a organização dos registros escritos que indica em que nível o aluno se encontra, mas, sim, as características dessa forma de pensar que são mobilizadas na resolução dos problemas, e que podem ser reveladas nos registros escritos. Por exemplo, a análise da resposta do aluno Carlos à Q5a indica que ele se encontra, assim como Júlia, no nível 3.

Q5a. João, Pedro e Cláudio têm, juntos, 160 carrinhos. Pedro tem 25 carrinhos a menos que João e 15 carrinhos a menos que Cláudio. Quantos carrinhos tem cada um deles?

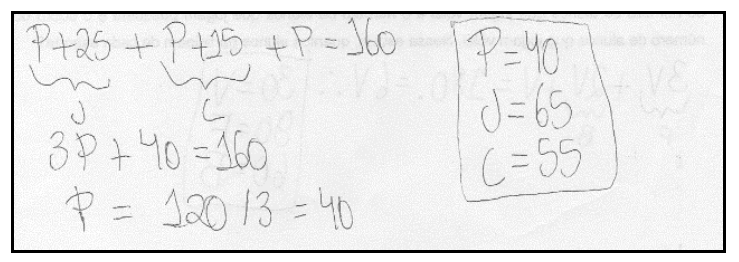

Figura 10 - Resposta do aluno Carlos ( $9^{\circ}$ ano $)$ à Q5a

Fonte: a pesquisa

É possível perceber que Carlos inicia a resposta ao PP convertendo-o direto para uma equação polinomial do $1^{\circ}$ grau, além de utilizar, como incógnita, a letra $\mathrm{P}$, que indica, na equação, a quantidade de carrinhos de Pedro, diferente da resposta de Júlia. Entretanto, percebemos que Carlos, assim como Júlia, estabelece as relações existentes entre as informações contidas no enunciado, isto é, entre a quantidade de carrinhos de cada personagem e o total, e revela essas relações na equação em que o "P" indica a quantidade de carrinhos de Pedro, o "P +25 " indica a quantidade de carrinhos de João, uma vez que se Pedro tem 25 carrinhos a menos que João, logo João tem 25 carrinhos a mais que Pedro, e o "P $+15 "$ representa a quantidade de carrinhos de Cláudio, visto que se Pedro tem 15 carrinhos a menos que Cláudio, então Cláudio tem 15 carrinhos a mais que Pedro, por isso a equação $\mathrm{P}+25+\mathrm{P}+15+\mathrm{P}=160$.

Carlos explica, no extrato de entrevista a seguir, como chegou à equação.

P: Me explica como você fez esse quinto?

Carlos: Como ele fala que Pedro tem 25 carrinhos a menos que João, isso significa que João menos 25 é igual a Pedro. Então, eu passei o 25 para o outro lado, que dá que João é igual a Pedro mais 25, que está escrito aqui (apontando para o "P + 25"). A mesma coisa com Pedro e Cláudio, que 
DOI: http://dx.doi.org/10.20396/zet.v26i3.8650717

Cláudio é Pedro mais 15 (apontando para o " $P+15$ ") e eu tenho que mostrar o de Pedro, adicionar o valor de Pedro (apontando para o "P”), que dá 160 .

$P$ : E como você chegou à resposta final?

Carlos: Eu juntei todos os $P$, juntar todos os números que eu consegui, subtrair os números dos dois lados, que dá P igual a 120 sobre 3, que dá 40.

P: Então me explica melhor como você chegou nesse $3 P$ e nesse 40?

Carlos: Eu somei todos os $P$ e somei 25 mais 15.

P: E para chegar em $P=120 / 3$, o que você fez?

Carlos: Eu subtraí 40 dos dois lados, que deu $3 P=120$, e depois eu dividi os dois lados por 3, por isso esse 120/3 aqui. Então P é igual a 40, que é o valor de Pedro.

P: E para achar a quantidade de João e Cláudio, você fez o quê??

Carlos: Eu adicionei 25 para o João, e adicionei 15 para o Cláudio no resultado, que deu isso aqui (apontando para o resultado final).

(Diálogo entre entrevistador e aluno, 2016)

Portanto, percebemos que Carlos, assim como Júlia, mobiliza, de forma consolidada, todas as características do pensamento algébrico. Ele revela mobilizar a capacidade de estabelecer relações quando realiza a conversão do problema para a linguagem algébrica levando em consideração todas as condições postas no enunciado, revelando, nesse caso, outra característica, a capacidade de modelar.

Nesse mesmo momento ele revela, também, mobilizar a capacidade de generalizar, uma vez que a incógnita aparece de forma clara em seu modelo e em suas explicações, e de construir significado para o objeto algébrico em jogo - tendo em vista que ele compreende o problema como uma relação de igualdade entre quantidade - e para a linguagem algébrica utilizada, pois ele demonstra compreender o que cada símbolo de seu modelo representa.

Por fim, ele revela, assim como Júlia, mobilizar a última característica dessa forma de pensar, a capacidade de operar com o desconhecido de forma analítica, quando ele realiza operações na equação inicial com o objetivo de gerar equações equivalentes até chegar no valor da incógnita. Observando apenas o registro escrito de Carlos não seria suficiente para afirmar que ele se vale das regras da aritmética em relação a uma igualdade, porém, em suas explicações ele deixa isso claro, quando afirma, por exemplo, que "Eu subtraí 40 dos dois lados, que deu $3 P=120$, e depois eu dividi os dois lados por 3 , por isso esse 120/3 aqui. Então P é igual a 40".

Por fim, assim como nos níveis 1 e 2, percebemos que no nível 3 temos três subníveis. No subnível 3A se encontram os alunos que, adotando a estratégia algébrica com registro algébrico formal, conseguem responder apenas aos problemas de partilha com encadeamento tipo fonte, enquanto que o subnível 3B é formado pelos alunos que, utilizando a mesma estratégia, conseguem responder os problemas de partilha com encadeamento tipo fonte e composição. Já no subnível 3C estão os estudantes que conseguem, adotando essa estratégia, 
DOI: http://dx.doi.org/10.20396/zet.v26i3.8650717

responder os problemas de partilha independente do encadeamento das relações, ou seja, fonte, composição ou poço.

\section{Conclusões}

Para visualizar melhor as características do pensamento algébrico mobilizadas em cada nível do modelo, temos o esquema a seguir.

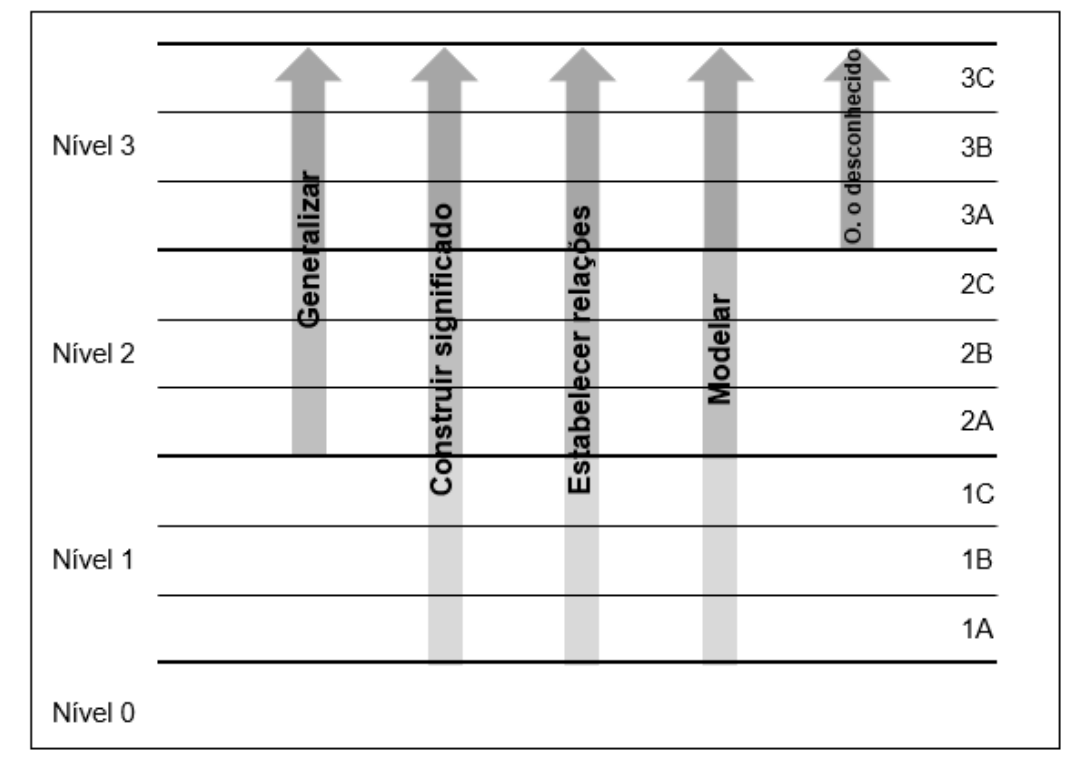

Figura 11 - Esquema do modelo

Fonte: os autores

Portanto, o modelo aqui proposto vai do nível 0 , o qual é caracterizado pela ausência de pensamento algébrico, passando pelo nível 1, no qual o pensamento algébrico do aluno que se encontra nesse nível é ainda incipiente, pelo nível 2, no qual o pensamento algébrico dos alunos que se encontram nele é intermediário, chegando, por fim, no nível 3, em que o pensamento algébrico dos alunos já é consolidado.

Propomos, também, a partir do nível 1, três subníveis para cada nível, que são definidos de acordo com o grau de complexidade que os encadeamentos das relações implicam aos problemas de partilha.

Acreditamos que diferentemente do modelo proposto por Fiorentini et al. (2005), que parece estar preso à linguagem simbólica algébrica como reveladora do pensamento algébrico, defendemos, em nosso modelo, a ideia que o aluno pode estar em um nível avançado do pensamento algébrico e mesmo assim utilizar uma linguagem diferente da tradicionalmente adotada na álgebra escolar, formada exclusivamente por símbolos genuinamente algébricos.

A elaboração do modelo aqui apresentado foi baseada no proposto por Godino et al. (2014), pois acreditamos, assim como eles, que o nível de desenvolvimento do pensamento algébrico é revelado pela estratégia adotada pelo aluno, inclusive, adotamos a nomenclatura dos níveis proposta por esses autores. 
Entretanto, defendemos que esses níveis são específicos ao problema, não no sentido de que o nível de complexidade do problema é o que determina o nível de desenvolvimento do pensamento algébrico, apesar de o influenciar, mas, sim, específico ao problema no sentido que o aluno pode encontrar-se em um determinado nível em um tipo de atividade, como os de generalização de padrões e, ao mesmo tempo, encontrar-se em outro nível quando solicitado a resolver outro tipo de situação, como os problemas de partilha, já que as relações necessárias para resolver essas situações são diferentes.

Por fim, uma das limitações de nosso modelo é que ele foi proposto com o objetivo de identificar o nível de pensamento algébrico dos alunos referente a apenas um tipo de problema de estrutura algébrica, os problemas de partilha. Porém, a álgebra é composta, como nos coloca Radford (2006), por um extenso número de objetos. Por conta disso, deixamos, para que sejam respondidas em pesquisas futuras, as seguintes questões: é possível adaptar o modelo aqui proposto para outros problemas de estrutura algébrica? E: é possível propor um modelo geral que possibilite a identificação do nível de desenvolvimento do pensamento algébrico dos alunos em relação a diferentes problemas de estrutura algébrica?

\section{Referências}

Almeida, J. R. \& Câmara, M. (2014). Análise dos problemas propostos para o ensino de equações polinomiais do $1^{\circ}$ grau nos livros didáticos de matemática. Boletim GEPEM, 64, 3-17.

Almeida, J. R. \& Câmara, M. (2017). Pensamento algébrico: em busca de uma definição. Revista Paranaense de educação Matemática, 6(10), 34-60.

Araújo, E. A. (2008). Ensino de álgebra e formação de professores. Educação Matemática Pesquisa, 10(2), 331 - 346. São Paulo.

Arcavi, A. (2005). El desarrollo y el uso del sentido de los símbolos. Conferência plenária no encontro de investigação em educação matemática. Caminha, Portugal. Retirado em 23/07/2014, de: http://www.educ.fc.ul.pt/docentes/jponte/DA/DAbibliografia.htm.

Borralho, A. \& Barbosa, E. (2011) Padrões e o desenvolvimento do pensamento algébrico. Anais da XIII Conferência Iteramericana de Educação Matemática. (pp. 1-12) Recife: SBEM.

Fiorentini, D., Fernandes, F. L. P. \& Cristovão, E. M. (2005). Um estudo das potencialidades pedagógicas das investigações matemáticas no desenvolvimento do pensamento algébrico. Seminário Luso-Brasileiro de Investigações Matemáticas no Currículo e na Formação de Professores. Lisboa. Retirado em 02/11/2010, de: http://www.educ.fc.pt/docentes/jponte/temporario/SEM-LB/Fiorentini-FernandesCristovao2.doc.

Godino, J. D., Aké, L. P., Gonzato, M. \& Wilhelmi, M. R. (2014). Niveles de algebrización de la actividad matemática escolar: implicaciones para la formación de maestros. Enseñanza de las Ciencias, 32(1), 199-219. Espanha. Disponível: http://www.raco.cat/index.php/Ensenanza/issue/view/21903/showToc 
DOI: http://dx.doi.org/10.20396/zet.v26i3.8650717

Kaput, J. (1999). Teaching and learning a new algebra with understanding. In E. Fennema, \& T. Romberg (Eds.), Mathematics classrooms that promote understanding. (pp. 1-34) Mahwah, NJ: Lawrence Erlbaum.

. (2008). What is algebra? What is algebraic reasoning? In J. Kaput, D. Carraher, \& M. Blanton (Eds.), Algebra in the Early Grades. (pp. 5-17) Lawrence Erlbaum Associates: New York.

Lins, R. C. (1992). A framework for understanding what algebraic thinking is. Tese de Doctor of Philosophy. School of Education, University of Nothingam: Nothingam, UK.

. (1994a). Campos semânticos y el problema del significado em álgebra. UNO Didáctica de las Matemáticas. 1, 1-7. Barcelona.

. (1994b). O modelo teórico dos campos semânticos: uma análise epistemológica da álgebra e do pensamento algébrico. Dynamis. 1(7), 29-39. Blumenau.

Lins, R. C. \& Gimenez, J. (2005). Perspectivas em Aritmética e Álgebra para o século XXI. Papirus: Campinas.

Marchand, P. \& Bednarz, N. (1999). L'enseignement de l'algèbre au secondaire: une analyse des problèmes présentés aux élèves. Bulletin AMQ, 39(4), 30-49. Québec.

Oliveira, I. \& Câmara, M. (2011). Problemas de estrutura algébrica: uma análise comparativa entre as estratégias utilizadas no Brasil e no Québec. Anais da XIII Conferência Iteramericana de Educação Matemática. Recife: SBEM.

Ponte, J. P. \& Velez, I. (2011) Representações em tarefas algébricas no $2^{\circ}$ ano de escolaridade. Boletim GEPEM. 59, 53-68.

Radford, L. (2006). Algebraic thinking and the generalization of patterns: a semiotic perspective. North America Conference of the International Group of Psychology of Mathematics Education-PME. 1, 1-21. México.

(2009). Signs, gestures, meanings: Algebraic thinking from a cultural semiotic perspective. Anais do Sixth Congress of the European Society for Research in Mathematics Education. Lyon, França, Disponível em: <www.inrp.fr/editions/cerme6>

. (2011) Grade 2 students' non-symbolic algebraic thinking. In J. Cai \& E. Knuth, (Eds). A global dialogue from multiple perspectives. (pp. 303-322), Editora Springer. Berlin.

Ruiz, N., Bosch, M. \& Gascón, J. (2010) La algebrización de los programas de cálculo aritmético y la introducción del álgebra en secundaria. In M. Moreno, A. Estrada, J. Carrillo \& T. Sierra (Eds.), Investigación en Educación Matemática. (pp. 545-556). Lleida: SEIEM.

Santos Junior, C. P. (2013) Estratégias utilizadas por alunos do $7^{\circ}, 8^{\circ}$ e $9^{\circ}$ ano do ensino fundamental na resolução de problemas de partilha. Dissertação de mestrado em Educação Matemática e Tecnológica. Recife: UFPE.

Silva, D. P. \& Savioli, A. M. P. D. (2012). Caracterizações do pensamento algébrico em tarefas realizadas por estudantes do Ensino Fundamental I. Revista Eletrônica de Educação. 6(1). 206-222.

Vermersch, P. (1994). L'entretien d'explicitation en formation initiale et en formation continuale. ESF: Paris. 


\section{APÊNDICE: testes A e B}

Quadro 2 - Testes utilizados na pesquisa

\begin{tabular}{|c|c|c|c|}
\hline \multicolumn{2}{|l|}{ Teste A } & \multicolumn{2}{|l|}{ Teste B } \\
\hline Questão & Estrutura & Questão & Estrutura \\
\hline $\begin{array}{l}\text { 1. Frederico, Lúcia e Rogério } \\
\text { têm, juntos, } 55 \text { revistas em } \\
\text { quadrinhos. Lúcia tem } 15 \\
\text { revistas a mais que Frederico e } \\
\text { Rogério tem o dobro de revistas } \\
\text { de Frederico. Quantas revistas } \\
\text { tem cada um? }\end{array}$ & $\begin{array}{l}\text { Encadeamento tipo } \\
\text { fonte, com a } 1^{\mathrm{a}} \\
\text { relação aditiva e a } \\
2^{\mathrm{a}} \text { relação } \\
\text { multiplicativa. }\end{array}$ & $\begin{array}{l}\text { 1. Frederico, Rogério e Lúcia } \\
\text { têm, juntos, } 55 \text { revistas em } \\
\text { quadrinhos. Rogério tem o } \\
\text { dobro de revistas de Frederico } \\
\text { e Lúcia tem } 15 \text { revistas a mais } \\
\text { que Frederico. Quantas } \\
\text { revistas em quadrinhos têm } \\
\text { cada um? }\end{array}$ & $\begin{array}{l}\text { Encadeamento tipo } \\
\text { fonte, com a } 1^{\mathrm{a}} \\
\text { relação } \\
\text { multiplicativa e a } 2^{\mathrm{a}} \\
\text { relação aditiva. }\end{array}$ \\
\hline $\begin{array}{l}\text { 2. Em uma escola, } 180 \text { alunos } \\
\text { praticam esporte. O número de } \\
\text { alunos que jogam futebol é o } \\
\text { triplo do número de alunos que } \\
\text { jogam vôlei e o número de } \\
\text { alunos que jogam basquete é o } \\
\text { dobro do número de alunos que } \\
\text { jogam vôlei. Nessa escola, } \\
\text { quantos alunos participam de } \\
\text { cada esporte? }\end{array}$ & $\begin{array}{l}\text { Encadeamento tipo } \\
\text { fonte, com a } 1^{\mathrm{a}} \text { e a } \\
2^{\mathrm{a}} \text { relação } \\
\text { multiplicativa. }\end{array}$ & $\begin{array}{l}\text { 2. Joana, Paulo e Roberto vão } \\
\text { repartir } 37 \text { balas de modo que } \\
\text { Paulo receba } 5 \text { balas a mais } \\
\text { que Joana e Roberto receba } 2 \\
\text { balas a mais que Joana. } \\
\text { Quantas balas receberá cada } \\
\text { um? }\end{array}$ & $\begin{array}{l}\text { Encadeamento tipo } \\
\text { fonte, com a } 1^{\mathrm{a}} \text { e a } \\
2^{\mathrm{a}} \text { relação aditiva. }\end{array}$ \\
\hline $\begin{array}{l}\text { 3. Três times de basquetes } \\
\text { participam da final do } \\
\text { campeonato fazendo, juntos, } 260 \\
\text { pontos. O time B fez } 20 \text { pontos a } \\
\text { mais que o time } \mathrm{A} \text { e o time } \mathrm{C} \text { fez } \\
\text { o dobro de pontos do time B. } \\
\text { Quantos pontos fez cada time? }\end{array}$ & $\begin{array}{l}\text { Encadeamento tipo } \\
\text { composição, com a } \\
1^{\mathrm{a}} \text { relação aditiva e } \\
\text { a } \quad 2^{\mathrm{a}} \text { relação } \\
\text { multiplicativa. }\end{array}$ & $\begin{array}{l}\text { 3. Três times de basquetes } \\
\text { participam da final do } \\
\text { campeonato fazendo, juntos, } \\
240 \text { pontos. O time B fez o } \\
\text { dobro de pontos do time A e o } \\
\text { time C fez } 40 \text { pontos a mais } \\
\text { que o time B. Quantos pontos } \\
\text { fez cada time? }\end{array}$ & $\begin{array}{l}\text { Encadeamento tipo } \\
\text { composição, com a } \\
1^{\text {a }} \text { relação } \\
\text { multiplicativa e a } 2^{a} \\
\text { relação aditiva. }\end{array}$ \\
\hline $\begin{array}{l}\text { 4. Marta, Rafael e Ana têm, } \\
\text { juntos, } 270 \text { chaveiros. Rafael } \\
\text { tem o dobro do número de } \\
\text { chaveiros de Marta, e Ana tem o } \\
\text { triplo do número de chaveiros de } \\
\text { Rafael. Quantos chaveiros têm } \\
\text { cada um? }\end{array}$ & $\begin{array}{l}\text { Encadeamento tipo } \\
\text { composição, com a } \\
1^{\mathrm{a}} \mathrm{e} \text { a } 2^{\mathrm{a}} \text { relação } \\
\text { multiplicativa. }\end{array}$ & $\begin{array}{l}\text { 4. Em uma escola, } 160 \text { alunos } \\
\text { praticam esportes. O número } \\
\text { de alunos que joga basquete é } \\
10 \text { a mais dos que jogam } \\
\text { vôlei, e o número de alunos } \\
\text { que joga futebol é } 20 \text { a mais } \\
\text { dos que jogam basquete. } \\
\text { Nessa escola, quantos alunos } \\
\text { praticam cada esporte? }\end{array}$ & $\begin{array}{l}\text { Encadeamento tipo } \\
\text { composição, com a } \\
1^{\mathrm{a}} \text { e a } 2^{\mathrm{a}} \text { relação } \\
\text { aditiva. }\end{array}$ \\
\hline $\begin{array}{l}\text { 5. João, Pedro e Cláudio têm, } \\
\text { juntos, } 160 \text { carrinhos. Pedro tem } \\
25 \text { carrinhos a menos que João e } \\
15 \text { carrinhos a menos que } \\
\text { Cláudio. Quantos carrinhos tem } \\
\text { cada um deles? }\end{array}$ & $\begin{array}{l}\text { Encadeamento tipo } \\
\text { poço, com a } 1^{\mathrm{a}} \text { e a } \\
2^{\mathrm{a}} \text { relação aditiva. }\end{array}$ & $\begin{array}{l}\text { 5. Ana, Júlia e Maria têm, } \\
\text { juntas, } 180 \text { selos. Júlia tem } \\
\text { um terço dos selos de Ana e a } \\
\text { metade dos selos de Maria. } \\
\text { Quantos selos têm cada uma? }\end{array}$ & $\begin{array}{l}\text { Encadeamento tipo } \\
\text { poço, com a } 1^{\mathrm{a}} \text { e a } \\
2^{\mathrm{a}} \text { relação } \\
\text { multiplicativa. }\end{array}$ \\
\hline $\begin{array}{l}\text { 6. Clara, Marcos e Antônio têm, } \\
\text { juntos, } 125 \text { bolinhas. Marcos tem } \\
\text { a metade de bolinhas de Clara e } \\
5 \text { bolinhas a menos que Antônio. } \\
\text { Quantas bolinhas têm cada um? }\end{array}$ & $\begin{array}{l}\text { Encadeamento tipo } \\
\text { poço, com a } 1^{\mathrm{a}} \\
\text { relação } \\
\text { multiplicativa e a } 2^{\mathrm{a}} \\
\text { relação aditiva. }\end{array}$ & $\begin{array}{l}\text { 6. Sílvia, Pedro e Carlos } \\
\text { querem dividir } 70 \text { figurinhas } \\
\text { entre eles de modo que Sílvia } \\
\text { receba } 30 \text { figurinhas a menos } \\
\text { que Pedro e a metade da } \\
\text { quantidade de figurinhas de } \\
\text { Carlos. Quantas figurinhas } \\
\text { cada um vai receber? }\end{array}$ & $\begin{array}{l}\text { Encadeamento tipo } \\
\text { poço, com a } 1^{\mathrm{a}} \\
\text { relação aditiva e a } \\
2^{\mathrm{a}} \quad \text { relação } \\
\text { multiplicativa. }\end{array}$ \\
\hline
\end{tabular}

Fonte: Elaborado pelos autores 